\title{
Xylazine-ketamine immobilization and propofol anesthesia for surgical excision of sebaceous adenoma in a jaguar (Panthera onca)
}

\author{
M. Bharathidasan ${ }^{1}$, R. Thirumurugan², B. Justin William³, R. S. George ${ }^{4}$, A. Arunprasad ${ }^{1}$, T. A. Kannan ${ }^{5}$ and S. Viramuthu $^{6}$
}

1. Department of Veterinary Surgery and Radiology, Madras Veterinary College, Chennai, Tamil Nadu, India; 2. Arignar Anna Zoological Park, Chennai, Tamil Nadu, India; 3. Centre for Stem Cell Research and Regenerative Medicine, Madras Veterinary College, Chennai, Tamil Nadu, India; 4. Department of Clinics, Madras Veterinary College, Chennai,

Tamil Nadu, India; 5. Department of Veterinary Anatomy, Madras Veterinary College, Chennai, Tamil Nadu, India; 6. Centralized Clinical Laboratory, Madras Veterinary College, Chennai, Tamil Nadu, India.

Corresponding author: B. Justin William, e-mail: vetjust@gmail.com, MB: dasan.bharathi234@gmail.com, RT: thiruzoovet@googlemail.com,RSG: ravi.george@yahoo.com, AA: drapvet@yahoo.co.in,

TAK: kanns2000@gmail.com, SV: viramuthu@tanuvas.org.in

Received: 19-08-2014, Revised: 25-10-2014, Accepted: 05-11-2014, Published online: 27-11-2014

doi: 10.14202/vetworld.2014.986-990. How to cite this article: Bharathidasan M, Thirumurugan R, William BJ, George RS, Arunprasad A, Kannan TA, Viramuthu S (2014) Xylazine-ketamine immobilization and propofol anesthesia for surgical excision of sebaceous adenoma in a jaguar (Panthera onca), Veterinary World, 7(11): 986-990.

\begin{abstract}
Aim: A captive male jaguar (Panthera onca) was anaesthetized for surgical excision of a tumor at the left belly fold under xylazine-ketamine immobilization and propofol anesthesia. The objective was to assess the dose of xylazine and ketamine required to abolish ear flick reflex for safe approach when the jaguar was under chemical immobilization and efficacy of propofol induced anesthesia.

Materials and Methods: A male jaguar (P. onca) aged 14 years and weighing approximately $90 \mathrm{~kg}$ was subjected to chemical immobilization using a combination of xylazine and ketamine using a blow pipe. The jaguar was approached after the absence of ear flick reflex and transported to zoo Operation Theater. Propofol was administered intravenously to induce and maintain anesthesia. The tumor was excised using thermocautery and subjected to histopathology.

Results: Ear flick reflex was stimulated at 5 and 10 min after immobilization and observed shaking of head and movement of fore limb following administration of xylazine and ketamine. Dose of xylazine and ketamine required for chemical immobilization, characterized by absence of ear flick reflex was 1.0 and $3.5 \mathrm{mg} / \mathrm{kg}$ body weight respectively, and was achieved in $13 \mathrm{~min}$. The surgical plane of anesthesia was maintained for $11 \mathrm{~min}$ following administration of propofol at a dose of $2 \mathrm{mg} / \mathrm{kg}$ body weight intravenously. The jaguar recovered in $41 \mathrm{~min}$ following surgery. The excised tumor was confirmed as sebaceous adenoma on histopathological examination. The animal recovered uneventfully, and no recurrence of the tumor was noticed in 3 months follow-up period.
\end{abstract}

Conclusion: The total dose xylazine and ketamine required for chemical immobilization with absence of ear flick reflex was 1.0 and $3.5 \mathrm{mg} / \mathrm{kg}$ body weight respectively. Further, administration of propofol intravenously, at a dose of $2 \mathrm{mg} / \mathrm{kg}$ maintained anesthesia for 11 min. Histopathological examination of the excised tumor at the belly fold was confirmed as sebaceous adenoma.

Keywords: ear flick reflex, jaguar, ketamine, Panthera onca, propofol, sebaceous adenoma, xylazine.

\section{Introduction}

The jaguar (Panthera onca) is a big cat, of Panthera species living in Americas [1]. The most common causes of morbidity in captive jaguars were found to be dental, gastrointestinal, integumentary and musculoskeletal diseases. Prevalence of these diseases vary with age [2] and management practices [3,4]. Neoplastic proliferations of benign and malignancy are one of the common causes of morbidity and mortality in wild felids including jaguars [5]. Sebaceous adenomas are common benign tumors found more often in all domestic animals with higher prevalence in middle to older age dogs and cats [6]. Sebaceous glands are microscopic structures found just beneath the skin surface. They secrete an oily substance called

Copyright: The authors. This article is an open access article licensed under the terms of the Creative Commons Attributin License (http:// creative commons.org/licenses/by/2.0) which permits unrestricted use, distribution and reproduction in any medium, provided the work is properly cited. sebum that is transported to the skin surface via microscopic ducts. Adenoma can arise from the gland or the duct and can develop anywhere on a feline body [7].

Number of chemical immobilization technique is followed in wild felines with their merits and demerits. To perform surgeries the jaguar is to be anaesthetized and maintained in the surgical plane, and the anaesthetic administered should have the property of good induction and rapid recovery. Xylazine-ketamine immobilization is commonly practiced in wild felines for immobilization $[8,9]$ but only limited publications are available on anaesthetic induction and maintenance and the use of propofol for induction and maintenance of anesthesia in wild felines.

In the present study, the dose of xylazine and ketamine that required to induce immobilization characterized by absence of ear flick reflex, which was a reliable indicator of immobilization and further maintenance of anesthesia with propofol for surgical excision of adenoma in a jaguar was discussed. 


\section{Materials and Methods}

\section{Ethical committee approval}

Ethical committee approval was not required as the case reported in this article was a clinical case. Standard anesthetic and surgical procedure were performed.

\section{I mmobilization and anesthesia}

A captive male jaguar, aged 14-year-old and weighing approximately around $90 \mathrm{~kg}$ body weight was referred to the Department of Veterinary Surgery and Radiology, Madras Veterinary College from Arignar Anna Zoological Park, Chennai, Tamil Nadu, India for the surgical excision of a growth on the left belly fold.

The jaguar was moved to a squeeze cage $24 \mathrm{~h}$ prior to the procedure and feed and water were withheld for 24 and 6 h respectively. Xylazine and ketamine at the rate of 1.0 and $2.5 \mathrm{mg} / \mathrm{kg}$ body weight respectively was administered intramuscularly at the right thigh using a blow pipe. The ear flick reflex was induced using a stiff wooden stick sufficient to stretch the auricular muscles after 5 and 10 min of darting. As the depth of immobilization was not sufficient to approach, further ketamine at the dose of $1.0 \mathrm{mg} / \mathrm{kg}$ body weight was administered intramuscularly. The animal was approached when the ear flick reflex was absent (Figure-1). Atropine sulphate at the dose of $0.04 \mathrm{mg} / \mathrm{kg}$ body weight was administered intramuscularly. The jaguar was transported to the zoo operation theatre. To induce anesthesia propofol was administered at the rate of $2 \mathrm{mg} / \mathrm{kg}$ body weight intravenously through saphenous vein to effect. The rectal temperature, respiratory rate and heart rates were monitored after xylazine-ketamine immobilization, after administration of propofol and before release into the cage.

\section{Tumor excision}

Surgical site on the left belly fold merging at the level of stifle joint was prepared aseptically using surgical spirit, povidone iodine and the tumor was excised using thermocautery. Subcutaneous tissue and skin were closed as per standard technique. Skin incision was sealed with methyl methacrylate skin glue. Injection ceftriaxone and meloxicam were administered intravenously at the rate of $20 \mathrm{mg} / \mathrm{kg}$ and

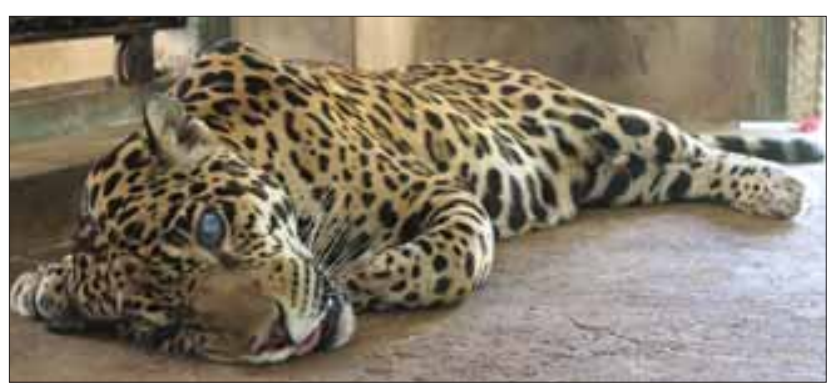

Figure-1: Immobilized jaguar (Panthera onca) with xylazine $(1.0 \mathrm{mg} / \mathrm{kg}$ body weight [B.W]) and ketamine (3.5 mg/kg B.W).
$0.2 \mathrm{mg} / \mathrm{kg}$ body weight respectively. The animal was shifted to cage. No intra or post-anaesthetic complication was noticed, and animal recovered uneventfully. No recurrence of the tumor was noticed till 3 months follow-up.

\section{Histopathology}

Cross section of the tumor revealed absence of ulceration and abscess. The excised tissue was preserved in $10 \%$ formal saline and subjected to histopathological examination. The tissue was prepared as per standard procedure [10]; the sections were stained with hematoxylin and eosin [11] and examined under light microscope.

\section{Results}

\section{I mmobilization and anesthesia}

The jaguar after the first dart with xylazine and ketamine combination became ataxic with in-coordination of the hind quarters by 3 min and recumbent by $5 \mathrm{~min}$. The ear flick reflex was stimulated, and the animal reacted by lifting the head and neck and fore limb. Again the reflex was stimulated after $10 \mathrm{~min}$ of darting and the reflex was sluggish with nodding of the head. Further administration of incremental dose of ketamine at the rate of $1.0 \mathrm{mg} / \mathrm{kg}$ body weight totally abolished the ear flick reflex in 3 min; sufficient to approach the animal. A total dose of $1.0 \mathrm{mg}$ and $3.5 \mathrm{mg} / \mathrm{kg}$ body weight of xylazine and ketamine respectively induced deep immobilization sufficiently safe for the operating personnel to approach the jaguar. Administration of propofol at the rate of $2 \mathrm{mg} / \mathrm{kg}$ intravenously induced and maintained the anesthesia for $11 \mathrm{~min}$ and animal recovered after $41 \mathrm{~min}$. The rectal temperature in celsius was 38.8, 37.4 and 38.6, heart rate per minute was 86, 80 and 102 and respiratory rate per minute was 16, 14 and 20 after xylazine-ketamine immobilization, after administration of propofol and before release into the cage respectively.

\section{Tumor excision}

Examination of the tumor revealed macroscopically single subcutaneous mass measuring around 5 cm diameters, pedunculated, well demarcated, freely movable and non-adherent to adjacent tissue with absence of ulceration and discharge (Figure-2). Thermocautary was found to be efficient in tumor excision without bleeding (Figure-3). Skin closure with methyl methacrylate skin glue was effective as evident by no post-operative bleeding, wound dehiscence and infection.

\section{Histopathology}

Histopathology of the tumor mass was characterized by multilobulated tumor, sharply demarcated from the surrounding tissue. Two types of cells were present in the lobules. Large mature sebaceous cells (sebocytes) at the centre and undifferentiated basaloid cells at the periphery were noticed (Figure-4). 


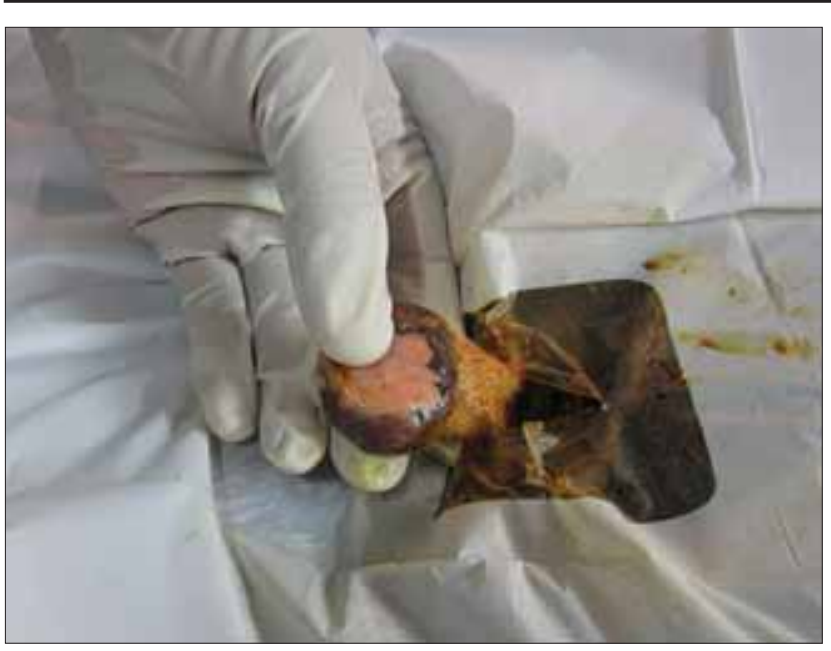

Figure-2: Exposed tumor mass at the left belly fold.

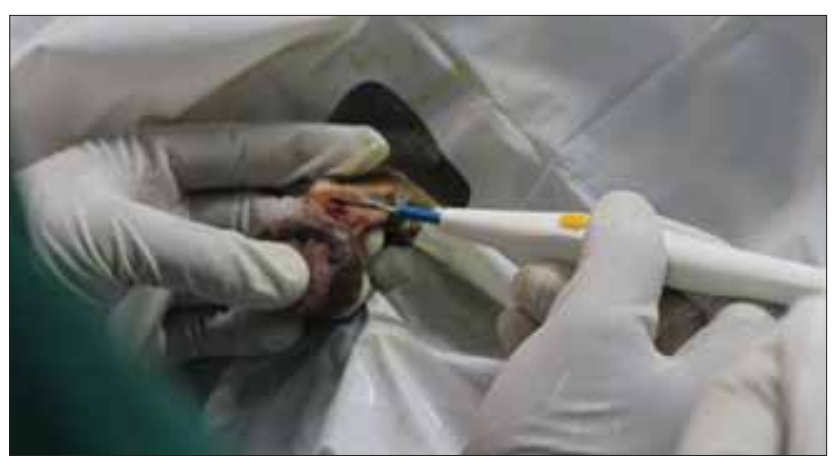

Figure-3: Surgical excision of the tumor using thermocautery.

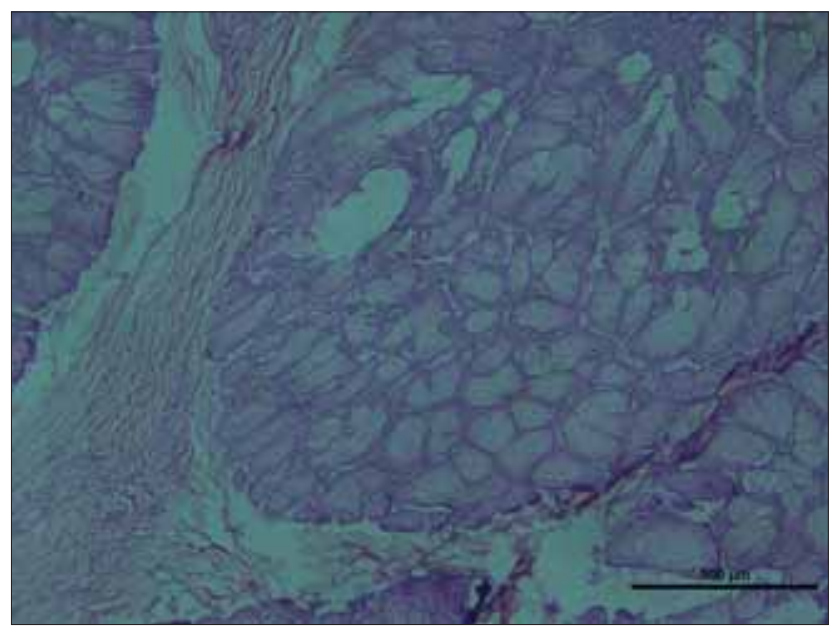

Figure-4: Large mature sebaceous cells (sebocytes) at the center and undifferentiated basaloid cells at the periphery characteristic of sebaceous adenoma $(500 \mu \mathrm{m})$.

\section{Discussion}

\section{I mmobilization and anesthesia}

Chemical immobilization is the safe method of capturing and immobilization of wild felids as chemical immobilization induce less stress, less morbidity and mortality due to trauma induced by dashing against the cages and vigorous struggling [12,13]. Various anaesthetics and ancillary drugs were used for induction of chemical immobilization of wild captive and free ranging big cats. Xylazine is preferred as an integral agent of immobilization due to its potential sedative and analgesic action with less complication [14]. The demerits of xylazine were salivation, vomition, arterio-ventricular block, paralytic ileus on repeated administration and arousal to auditory, visual and external stimuli $[15,16]$. Xylazine when administered along with ketamine prolonged the plasma halflife of ketamine and administration of incremental dose of ketamine at the rate of $1 \mathrm{mg} / \mathrm{kg}$ abolished the ear tactile reflex in 3 min and diminished the hypertonicity and tremors of skeletal muscles induced by ketamine [17]. Whereas ketamine moderated the bradycardic effect of xylazine by cardiotonic action mediated through sympathetic stimulation and vagolytic action [18]; thus xylazine and ketamine acted as a useful and safe combination for chemical immobilization of jaguar at the total dose of 1.0 and $3.5 \mathrm{mg} / \mathrm{kg}$ body weight intramuscularly [1,7,19]. Atropine sulphate at the dose of $0.04 \mathrm{mg} / \mathrm{kg}$ body weight contributed benefits due to its antimuscarinic effect [20].

Stimulation of ear sufficient to stretch the auricularis muscles of the ear with a wooden stick to assess the depth of anesthesia in wild felids for safe approach was practiced and the wild felines were approached only after the absence of ear flick reflex [21]. The dorsal cochlear nucleus (DCN) in felines is the second-order auditory structure that also receive non-stimuli auditory including somato-sensory inputs from dorsal column and spinal trigeminal nuclei. When cervical nerves 1-8 (C1-8), dorsal and ventral branches of C2, branches of trigeminal nerve and hind limb nerves are stimulated separately; the largest evoked potentials in the DCN is produced by stimulation of the branches of dorsal branches of C2, that innervate the pinna, the back of the head, the rostral dorsal part of the neck and the fore limbs. Stimuli that activate pinna muscle receptors, such as stretch or vibration of the muscles connected to pinna are effective in driving DCN units. The fibres of C2 also share its fibres with C3 and trigeminal. Stimulation of pinna and eye movements to visual targets contribute too early "orientation response" in felines, and it is mediated through DCN output projections [22]. If the ear flick reflex is absent it could be assumed that the felines were sufficiently immobilized, input stimuli to DCN was abolished and thus render the animal completely irresponsive to external stimuli that could arose the felines [23]. The dose of and xylazine and ketamine used in the study was similar to the earlier reports [1,9]. Xylazine with ketamine was used as immobilizing agent in lions [24-25], tigers [26] and cheetah [27].

All the immobilized animals are not anaesthetized, but all the anaesthetized animals are immobilized. To perform surgeries, the animal is to be induced and maintained in the surgical plane of anesthesia. Propofol is an alkyl phenol intravenous agent, which can induce anesthesia in one-arm-brain 
circulation, and the induction time is $<5 \mathrm{~min}$ in domestic animals. It is rapidly metabolized in the body tissue, and recovery is due to rapid detoxification and elimination unlike other agents which depends on the liver [28]. The respiratory rate was with in the clinical limits in the study. It possesses the structural formula like alpha tocopherol and act as antioxidant [29]. Due to the rapid recovery and antioxidant effect, propofol is used in critical ill and geriatric patients [30]. Propofol was used as anaesthetic in lion for induction and maintenance agent [21]. The duration of anesthesia and recovery following propofol anesthesia in the jaguar was $11 \mathrm{~min}$, which was sufficient to excise the tumor and recovery in terms of time for standing was $41 \mathrm{~min}$ from the time of administration of propofol. The short and uneventful recovery is a desirable property in wild life anesthesia [13].

\section{Tumor excision}

Tumor excision was performed with thermocautary due to the benefits of simple, fast, better and haemostsis and more aseptic than cutting and ligation [31-32] and methyl methacrylate helped in faster healing without wound infection and dehiscence. No reoccurrence was noticed during the 3 months follow-up period.

\section{Histopathology}

Macroscopically the tumor was a single subcutaneous mass measuring around $5 \mathrm{~cm}$ diameters, pedunculated, well demarcated, freely movable and non-adherent to adjacent tissue with absence of ulceration and discharge. Microscopically the tumor mass was characterized by multilobulated tumor, sharply demarcated from the surrounding tissue. Two types of cells were present in the lobules. Microscopically large mature sebaceous cells (sebocytes) at the centre and undifferentiated basaloid cells at the periphery and similar microscopic finding were documented in dogs [33]. Incidence of cutaneous adenocarcinoma of sebaceous gland was reported in jaguars and was attributed to age and husbandry practices in captivity [34]. The neoplasms reported in jaguars were thyroid adenoma and adenocortical adenoma, ovarian cystadenocarcinoma, haemangio-endothelioma, glucagonoma, squamous cell carcinoma of the tail, visceral mast cell tumor, and mammary tumor [5].

\section{Conclusion}

Xylazine and ketamine induced the immobilization in $13 \mathrm{~min}$, characterized by absence of ear flick reflex at a dose of $1.0 \mathrm{mg} / \mathrm{kg}$ and $3.5 \mathrm{mg} / \mathrm{kg}$ body weight respectively in a jaguar. Further induction of anesthesia with propofol at a rate of $2 \mathrm{mg} / \mathrm{kg}$ body intravenously maintained the anesthesia for $11 \mathrm{~min}$, sufficient to remove a tumor with recovery time of 45 min. Histopathological examination of tumor revealed sebaceous adenoma.

\section{Authors' Contributions}

MB and BJW performed the surgery, RT, RSG and AA managed the immobilization and anesthesia. TAK and SV were involved in the pre and post-operative care and management. All the authors participated in draft and revision of manuscript. All authors read and approved the final manuscript.

\section{Acknowledgement}

The authors are thankful to the Director, Arignar Anna Zoological Park, Chennai and The Dean, Madras Veterinary College, Chennai for the facilities provided and the financial support towards the purchase of drugs and surgical disposables.

\section{Competing I nterests}

The authors declare that they have no competing interests.

\section{Reference}

1. Hoogesteijin, R. and Mondolifi, E. (1992) The Jaguar. Armitano Publishers, Caracas.

2. Hope, K. and Deen, S. (2006) Retrospective study of morbidity and mortality of captive Jaguars (Panthera onca) in North America: 1982-2002. Zoo Biol., 25: 501-512.

3. Quigley H. (1987) Ecology and conservation of the jaguar in the Pantanal Region, mato Grosso do Sul. PhD, Dissertation. University of Idaho, Brazil.

4. Deem, S.D. and Karesh, W.B. (2005) The Jaguar Health Program Manual. Wildlife Conservation Society, USA.

5. Majie, A.K., Mondal, P., Ghosh, S.K. and Banerjee, D. (2014) Cutaneous adenocarcinoma of sebaceous gland in a captive male jaguar Panthera onca: A case report. J. S. Afr. Vet. Assoc., 85(1): 918.

6. Vail, D.M. and Withrow, S.J. (2001) Tumors of the mammary gland. In: Small Animal Clinical Oncology. WB Saunders, Philadelphia, p455-477.

7. Blackwood, L. (2011) Tumors of the skin and subcutaneous tissues. In: Dobson, J.M. and Lascelles, B.D.X., editors. BSAVA Manual of Canine and Feline Oncology. BSAVA, England, p130-158.

8. Fyumagawa, R.D., Bugwesa, Z.K., Mdaki, M.L., Mpanduji, D.G., Kilewo M. and Hoare, R. (2012) Comparison of anesthesia and cost of two immobilization protocols in free-ranging lions. South Afr. J. Wildlife Res., 42: 67-77.

9. Deem S.L. (2004) Capture and immobilization of free-living jaguars (Panthera onca) In: Heard, D. editor. Zoological Restraint and Anesthesia. International Veterinary Information Service, Ithaca, New York, USA.

10. Collins, J.A., Novak, A., Syed, S.A. and Olsion, M.T. (2013) Cytotechnologists and on-site evaluation adequacy. Korean J. Pathol., 47: 405-410.

11. Kloth, M. and Buettner, R. (2014) Changing histopathological diagnostics by genome based tumor classification. Genome, 5: 444-459.

12. Griner, E. and Lynn A. (1983) Pathology of Zoo Animals. Zoological Society of San Diego, USA, p490-492.

13. Dembiec, D.P., Shrider, R.J. and Zonella, A. (2004) The effect of transport stress on tiger physiology and behavior. Zoo Biol., 23: 335-346.

14. Hubbell, J.A.E. (2009) Practical standing chemical restraint of the horse. Anesthesia and pain management. In: Proceedings of the Annual Convention of AAEP. Vol. 55. Published in IVIS. p2-6.

15. Bienert, A., Bartmann, C.P. and Von Oppen, T. (2003) Recovery phase of horses after inhalant anesthesia with isofluorane (IsofloR) and postanaesthetic sedation with 
romifidine (Sedivet) or xylazine (Rompun). Dtsch. Tierarztl. Woschenschr., 110: 244-248.

16. Bufalari, A., Admi, C. and Angeli, G. (2007) Pain assessment in animals. Vet. Res. Commun., 31: 55-58.

17. Gleed, R.D. (1987) Tranquilisers and sedatives. In: Short, C.F. editor. Principles and Practices of Veterinary Anesthesia. $1^{\text {st }}$ ed. Williams and Wilkens, London, p16-21.

18. Gross, M.E. (2001) Tranquilizers, alpha 2 adrenergic agonists, and related agents. In: Adams, H.R. editor. Veterinary Pharmacology and Therapeutics. $8^{\text {th }}$ ed. Iowa State University Press, Ames. p299-342.

19. Lopez de Buen, L. and Sanchez, J.M.A. (1986) Nota zoologica. Anestesia de mamiferos silvestres con la combinacion ketamina-xilacina. Biotica, 11: 67-71.

20. Congdon, J.M., Marquez, M., Niyom, S. and Boscan, P. (2011) Evaluation of sedative and cardiovascular effects of intramuscular administration of dexmedetomidine with and without concurrent atropine administration in dogs. J. Am. Vet. Med. Assoc., 239(1): 81-88.

21. Epstein, A., White, R., Horowtiz, I.H., Hass, P.H. and Ofri, R. (2002) Effects of propofol as an anaesthetic agent in adult lions (Panthera leo): A comparison with two established protocols. Res. Vet. Sci., 72: 137-140.

22. Kanold, P.O. and Young, E.D. (2001) Proprioceptive information from the pinna provides somatosensory input to cat dorsal cochlear nucleus. J. Neuro. Sci., 21(19): 7848-7858.

23. Gatesman, T. and Wiesner, H. (1982) Immobilization of polar (Thalarctos maritimus) and bears using etorphine and xylazine. J. Zoo Med., 13: 11-18.

24. Steeil, J.C., Schumacher, J., Katherine, B., Ramsay, E.C., Sura, P., Hodshon, R., Donnell, R.L. and Lee, N.D. (2013) Diagnosis and treatment of a dermal malignant melanoma in an African Lion (Panthera leo). J. Zoo Wildlife Med., 44(3): 721-727.

25. Robert, D.F., Zablon, K.B., Maulid, L.M., Donald, G.M., Morris, K. and Richard, H. (2012) Comparison of anesthesia and cost of two immobilization protocols in free ranging lions. S. Afr. J. Wildlife Res., 42(1): 67-70.

26. Gupta, A., Jadav, K., Nigam, P., Swarup, D. and Shrivasthava, A.B. (2013) Eyelid neoplasm in a White Tiger (Panthera tigris) - A case report. Vet. Arhiv., 83(1): 115-124.

27. Whiton, A., Schumacher, J., Evans, E.E., Novak, J.M., Crews, A., Ramsay, E. and Donnell, R. (2013) Case report Mesothelioma in two nondomestic felids: North American Cougar (Felisconcolor) and Cheetah (Acinonysjubatus). Case Rep. Vet. Med., 2013: 1-6.

28. Brussel, T., Theissen, J.L., Vigfusson, P., Lunkenheimer, P., Aken, H.V. and Lawin, P. (1989) Hemodynamic and cardiodynamic effects of propofol and etomidate: negative ionotropic properties of propofol. Anaesth. Analg., 69: 35-40.

29. Basu, S., Mutschler, D.K., Larsson, A.O., Kiiski, R., Nordgern, A. and Eriksson, M.B. (2001) Propofol (DiprivanEDTA) counteracts oxidative injury and deterioration of the arterial oxygen tension during experimental septic shock. Resuscitation, 50: 341-348.

30. Kamibayashi, T., Hayshi, Y., Sumikawa, K., Yamatodani, A., Kawabata K. and Yoshiya, I. (1991) Enhancement of propofol-epinephrine induced arrhythmias in dogs. Anaesthesiology, 75: 1035-1040.

31. Massarweh, N.N., Cosgriff, N. and Slakey, D.P. (2006) Electro-surgery: History, principles, and current and future uses. J. Am. Coll. Surg., 202: 520-530.

32. Al-Hyani, O.H. (2011) A comparative study for lung biopsy in dogs. Iran J. Vet. Sci., 11(1): 35-40.

33. Ozylglt, M., Akkoc, A. and Yilmaz, R. (2005) Sebaceous gland adenoma in a dog. Turk. J. Vet. Anim. Sci., 29: 1213-1216.

34. Owston, M.A., Ramsay, E.C. and Rotstein, D.S. (2008) Neoplasia in felids at the knoxville zoological gardens, 1979-2003'. J. Zoo Wildlife Med., 39: 608-613. 